\title{
Emerging Contaminant or an Old Toxin in Disguise? Silver Nanoparticle Impacts on Ecosystems
}

\author{
Benjamin P. Colman, ${ }^{*}, \dagger, \nabla$ Benjamin Espinasse, ${ }^{\ddagger}, \nabla$ Curtis J. Richardson, ${ }^{\S, \|, \nabla}$ Cole W. Matson, ${ }^{\|, \perp, \nabla}$ \\ Gregory V. Lowry, $\#, \gg$ Dana E. Hunt, " Mark R. Wiesner, ${ }^{\ddagger}, \dot{\nabla}$ and Emily S. Bernhardt ${ }^{\dagger}, \nabla$ \\ ${ }^{\dagger}$ Department of Biology, Duke University, Durham, North Carolina 27708, United States \\ ${ }^{\ddagger}$ Civil and Environmental Engineering Department, Duke University, Durham, North Carolina 27708, United States \\ ${ }^{\S}$ Duke University Wetland Center, Nicholas School of the Environment, Duke University, Durham, North Carolina 27708, United \\ States \\ "Nicholas School of the Environment, Duke University, Durham, North Carolina 27708, United States \\ ${ }^{\perp}$ Department of Environmental Science and the Center for Reservoir and Aquatic Systems Research (CRASR), Baylor University, \\ Waco, Texas 76798, United States \\ ${ }^{\#}$ Civil \& Environmental Engineering, Carnegie Mellon University, Pittsburgh, Pennsylvania 15213, United States

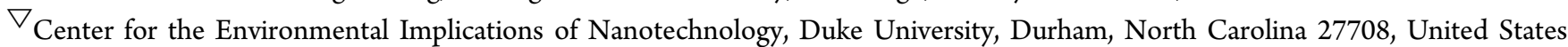

\section{Supporting Information}

\begin{abstract}
The use of antimicrobial silver nanoparticles (AgNPs) in consumer-products is rising. Much of these AgNPs are expected to enter the wastewater stream, with up to $10 \%$ of that eventually released as effluent into aquatic ecosystems with unknown ecological consequences. We examined AgNP impacts on aquatic ecosystems by comparing the effects of two AgNP sizes (12 and $49 \mathrm{~nm})$ to ionic silver $\left(\mathrm{Ag}^{+}\right.$; added as $\left.\mathrm{AgNO}_{3}\right)$, a historically problematic contaminant with known impacts. Using 19 wetland mesocosms, we added $\mathrm{Ag}$ to the $360 \mathrm{~L}$ aquatic compartment to reach $2.5 \mathrm{mg} \mathrm{Ag} \mathrm{L}^{-1}$. Silver treatments and two coating controls were done in triplicate, and compared to four replicate controls. All three silver treatments were toxic to aquatic plants, leading to a significant release of dissolved organic carbon and chloride following exposure. Simultaneously, dissolved methane concentrations increased forty-fold relative to controls in all three Ag treatments. Despite dramatic toxicity differences observed in lab studies for these three forms of $\mathrm{Ag}$, our results show surprising convergence in the direction, magnitude, and duration of ecosystem-scale impacts for all Ag treatments. Our results suggest that all forms of $\mathrm{Ag}$ changed solute chemistry driving transformations of $\mathrm{Ag}$ which then altered $\mathrm{Ag}$ impacts.
\end{abstract}

\section{INTRODUCTION}

The small size of manufactured nanomaterials $(1-100 \mathrm{~nm})$ gives them unique physical and chemical properties, which have led to their use in an ever increasing number of consumer products and industrial processes. ${ }^{1}$ With this rapid increase in the production and use of nanomaterials, it is inevitable that engineered nanomaterials are entering the environment. ${ }^{2}$ However, our ability to create and deploy new nanomaterials far outstrips our understanding of what they may do outside of their intended use, leading to concerns that these novel contaminants will have unpredictable and potentially dire consequences when they enter natural environments.

Silver nanoparticles (AgNPs) are of particular concern because they are produced specifically for their antimicrobial and biocidal properties. The increasing use of AgNPs leads to two obvious questions: At what concentrations are AgNPs entering the environment? What are their impacts on the exposed organisms? A number of risk assessments ${ }^{3,4}$ now suggest that AgNPs are entering wastewaters and are ultimately entering the environment as either wastewater treatment biosolids $^{2}$ or effluent. ${ }^{5,6}$ At present, there are no empirical data on silver nanoparticle concentrations and no assessments of their impacts in natural environments.

The rapidly expanding toxicological literature on nanomaterial impacts suggests that AgNP pollution has the potential to harm many organisms and that AgNP loading could lead to significant changes in important ecosystem processes, such as primary productivity, ${ }^{7,8}$ decomposition, ${ }^{9}$ and nitrogen cycling. ${ }^{10,11}$ Toxicological research on the environmental impacts

Received: December 6, 2013

Revised: March 18, 2014

Accepted: April 2, 2014

Published: April 2, 2014 
of AgNPs, however, has primarily focused on high dose AgNP exposures to single-species cultures grown in well-characterized laboratory media. Although lab studies are essential for elucidating the mechanisms of toxicity, it is quite difficult to extrapolate their findings to natural ecosystems. In natural ecosystems, exposure concentrations are likely to be low, environmental media are both chemically complex and heterogeneous, and the myriad direct and indirect interactions that exist within communities of organisms in natural environments are likely to alter the magnitude and potentially the direction of nanomaterial impacts. ${ }^{12}$

$\mathrm{Up}$ to $10 \%$ of the AgNPs entering wastewater treatment plants are predicted to be released in wastewater effluent into aquatic ecosystems, ${ }^{2,5,6,13}$ thus we chose to explore the impacts of nanoparticle addition in wetlands. To the water column of triplicate $4.5 \mathrm{~m}^{2}$ wetland mesocosms, we added either $12 \mathrm{~nm}$ gum arabic coated or $49 \mathrm{~nm}$ polyvinylpyrrolidone coated AgNPs (hereafter, GA-AgNPs and PVP-AgNPs, respectively). We compared the fate and impact of these AgNPs to the addition of ionic silver $\left(\mathrm{Ag}^{+}\right)$added as $\mathrm{AgNO}_{3}$. Each $\mathrm{Ag}$ treatment consisted of a single dose sufficient to raise initial

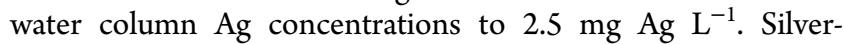
treated mesocosms were compared to four replicate control mesocosms, and triplicate GA-coating and PVP-coating controls, which received the same amount of the coatings added in the AgNP treatments, only without AgNPs. With one minor exception described in the results, coating controls were identical to control mesocosms. Thus, the focus of the work presented here is on comparisons between controls, GAAgNPs, PVP-AgNPs, and $\mathrm{AgNO}_{3}$ treatments.

Dissolved silver is a well-studied contaminant with a long history of environmental impact studies, ${ }^{14}$ and thus a primary goal of our study was to determine the extent to which the ecological impacts of AgNP exposure differ from the better studied effects of $\mathrm{Ag}^{+}$exposure. Direct comparisons within individual studies have led to mixed conclusions: some studies found higher toxicity and/or biouptake for AgNPs than $\mathrm{AgNO}_{3} ;{ }^{7,8,15,16}$ other studies report the opposite conclusion. ${ }^{17-19}$ Much of this discrepancy may be explained by differences in AgNP size or coatings; for that reason, we chose to compare the effects of two very different AgNPs with different published toxicity thresholds: the larger PVP-AgNPs are in general less toxic than the smaller GA-AgNPs, which in turn tend to be less toxic than $\mathrm{AgNO}_{3}{ }^{18,19}$ Thus, we expected to find that dissolved silver would reduce microbial and plant biomass and growth to a greater degree than GA-AgNPs, while both GA-AgNPs and $\mathrm{AgNO}_{3}$ treatments would have stronger impacts than the addition of larger PVP-AgNPs. Furthermore, we expected patterns of bioaccumulation into plant tissues to follow similar trends.

\section{MATERIALS AND METHODS}

Setup. The overall design and construction of our slantboard wetland mesocosms were as previously detailed. ${ }^{20}$ Briefly, treated lumber was used to create $3.66 \times 1.22 \times 0.81 \mathrm{~m}$ boxes. The boxes were partially filled with screening material, and graded to give a flat bottom that was $0.8 \mathrm{~m}$ long, connected to a slope upward at an angle of $13^{\circ}$ and a run of $2.8 \mathrm{~m}$. Over the screening, an EPDM liner was placed, and over the liner soil was filled to a constant thickness of $22 \mathrm{~cm}$. Mesocosms were built between August of 2009 and March of 2010 .

The soil used in this experiment was a blend of three topsoils chosen to give a similar texture and organic matter content to soils used in previous terrestrial and wetland mesocosm experiments. ${ }^{15,20}$ Soils were blended and provided by Soils and Sand (Durham, U.S.A.), and were a blend of three soils ("Sandhills", from Lemon Springs, NC, U.S.A.; "Clay" and "Topsoil”, from Durham, NC, U.S.A.). The final soil had a texture of $63.9 \%$ sand, $28.3 \%$ silt, and $13.0 \%$ clay, with $5.1 \%$ loss on ignition.

The mesocosms consist of the following: a permanently flooded portion (aquatic zone), a periodically flooded portion (transition zone), and a rarely flooded portion (upland zone). Mesocosms were planted in March of 2010. In the aquatic compartment, six stems of Egeria densa were planted in a two by three grid, Potamogeton diversifolius was unintentionally introduced with the E. densa, and $2 \mathrm{~g}$ of the duckweed Landoltia punctata was floated on the water's surface (Carolina Biological, Burlington, U.S.A.). The transition and upland zones were planted as described in the Supporting Information, SI. Algae and zooplankton were added in $250 \mathrm{~mL}$ of unfiltered water per mesocosm from a local wetland. Other organisms were added or were allowed to colonize the mesocosms, as described in the SI.

To normalize the water chemistry and algal composition in the mesocosms, a submersible pump was used to circulate water between the 19 mesocosms. Water was circulated using a combination of pumping and siphoning twice prior to dosing in order to ensure reasonable homogenization of the water, as verified by convergence of water chemistry.

Experimental Treatments. There were six different treatments overall: Control, received DI water; PVP-coating control, received PVP equivalent to that added with the PVPAgNPs; GA-coating control received gum arabic equivalent to that added with the GA-AgNPs; $\mathrm{AgNO}_{3}$, received sufficient $\mathrm{AgNO}_{3}$ to bring watercolumn concentration to $2.5 \mathrm{mg} \mathrm{Ag} \mathrm{L}^{-1}$; GA-AgNPs, received sufficient $12 \pm 9.2 \mathrm{~nm}$ (mean \pm standard deviation) gum arabic coated AgNPs to bring the watercolumn $\mathrm{Ag}$ concentrations to $2.5 \mathrm{mg} \mathrm{L} \mathrm{L}^{-1}$; PVP-AgNPs received sufficient $49.3 \pm 22.5 \mathrm{~nm}$ PVP-coated AgNPs to reach 2.5 $\mathrm{mg} \mathrm{Ag} \mathrm{L}{ }^{-1}$. Silver-treated mesocosms all had $900 \mathrm{mg} \mathrm{Ag}$ added to bring the watercolumn to $2.5 \mathrm{mg} \mathrm{Ag} \mathrm{L}^{-1}$. Since the $\mathrm{AgNO}_{3}$ treatment received a sizable $\mathrm{NO}_{3}^{-}$input, we added an equivalent amount of $\mathrm{NO}_{3}{ }^{-}$to all other treatments in the form of $\mathrm{KNO}_{3}$. The characterization of the AgNP stocks used in this experiment have been previously described. ${ }^{21,22}$ Treatments were applied mid-day on August 17, 2010, (Day 0 ) and were applied by pouring treatment water into a funnel with a $10 \mathrm{~mL}$ pipet tip on the end of the funnel to slow the flow into the watercolumn. The tip was submerged, but kept within $1 \mathrm{~cm}$ of the surface and moved in a grid to add material as uniformly as possible to the watercolumn.

The concentration and rate of addition of AgNPs in this experiment are admittedly high, more consistent with existing toxicological literature than they were with predicted environmental exposure scenarios. Additionally, rather than $\mathrm{Ag}^{(0)} \mathrm{NPs}$, what has been observed in waste streams has been $\mathrm{Ag}_{2} \mathrm{~S}$ $\mathrm{NPs}{ }^{5,23,24}$ which have been shown to have diminished toxicity in lab studies ${ }^{25-27}$ when compared to $\mathrm{Ag}^{(0)} \mathrm{NPs}$. While the 2.5 $\mathrm{mg} \mathrm{Ag} \mathrm{L}{ }^{-1}$ concentration was easily at the low end of the range used in many toxicological studies and is quite low in comparison to concentrations used in many other nanoparticle impact studies conducted to date, it is more similar to untreated photoprocessing effluents than it is to expected concentrations in wastewater effluent, let alone wetlands and streams. ${ }^{5,6,28}$ In this experiment, these high concentrations were a compromise 
between expected analytical tractability-measuring the fate, transformation, and impacts of AgNPs in a complex environment over the full course of the 15 month experiment-and environmental realism. While actual loading rates and watercolumn concentrations are likely to be much lower, it should also be mentioned that those exposures are likely to be in the form of chronic addition of silver, and so the cumulative load over time may be similar. Additionally, by studying $\mathrm{Ag}^{(0)} \mathrm{NPs}$ in comparison to $\mathrm{Ag}^{+}$, we are able to better bound the range of what is possible in this worst case scenario, and describe the similarities and differences of AgNP impacts and $\mathrm{Ag}^{+}$in this complex wetland ecosystem environment.

Sampling. For the first 30 days of this experiment, we focused our analyses on the biogeochemistry of the aquatic zone and the treatment effects on plants, phytoplankton, and microbes; these were the organisms that were most abundant, most directly influencing biogeochemistry, and directly affected by the addition of silver. Full details on sampling protocols and sample handling and treatment are available as SI. Briefly, water was collected from $10 \mathrm{~cm}$ depth for dissolved solutes, dissolved organic carbon (DOC), and silver concentration. Water for dissolved gases was sampled at the surface using established protocols $^{29}$ with modifications. ${ }^{30}$ Vegetation in the aquatic compartment was photographed on Days 2, 7, and 16 from approximately $1 \mathrm{~m}$ above the aquatic end of the mesocosms.

Analyses. While a subset of water chemistry parameters are highlighted in this paper, water chemistry parameters measured included: the anions $\mathrm{Cl}^{-}, \mathrm{SO}_{4}{ }^{2-}, \mathrm{Br}^{-}$, and $\mathrm{NO}_{3}{ }^{-}$, measured on a Dionex ICS 2000 Ion Chromatograph; $\mathrm{NH}_{4}{ }^{+}$and $o-\mathrm{PO}_{4}$ measured on a Lachat QuickChem 8500; nonpurgeable dissolved organic carbon (our metric of dissolved organic carbon, DOC) and total dissolved nitrogen (TDN) measured on a Shimadzu TOC-VCPH Analyzer with a TNM-1 module. Dissolved gas samples from headspace equillibrations (see SI) were injected into a Shimadzu 17A Gas Chromatograph using a Tekmar 7050 Headspace Autosampler, as has been previously described. ${ }^{30}$ Water column silver was measured on a PerkinElmer 3100 flame-AAS up to Day 8, after which point samples were measured on a PerkinElmer 5100 GF-AAS. Ultrafiltered samples were all measured by GF-AAS. Phytoplankton were enumerated using a BD FACSCalibur Flow Cytometer as previously described. ${ }^{31}$ Non-photosynthetic prokaryotes were quantified by flow cytometry by first staining the samples with Sybr Green-I as has been previously described. $^{32}$ Silver speciation was estimated using Visual MINTEQ V3.0 (KTH Royal Institute of Technology, Stockholm, Sweden), which was parametrized using measured solute concentrations and $\mathrm{pH}$.

Statistics. In examining solute and gas concentrations over time, we had three questions. First, were there any differences between the true control treatment and the coating controls over time? Second, were there differences between the control(s) and silver treatments over time? Third, were there differences among the silver treatments over time? To answer all of these questions, we conducted two-way ANOVA with time and treatment as factors, and using Holm-Sidak posthoc tests for multiple comparisons within an individual factor.

\section{RESULTS}

Silver Concentrations in the Water Column. Within 24 $\mathrm{h}$ of dosing the water column of each mesocosm, total silver concentrations dropped from our target of $2.5 \mathrm{mg} / \mathrm{L}$ down to $2.02 \pm 0.12,1.99 \pm 0.07$, and $0.85 \pm 0.24 \mathrm{mg} \mathrm{Ag} \mathrm{L}^{-1}$ for the

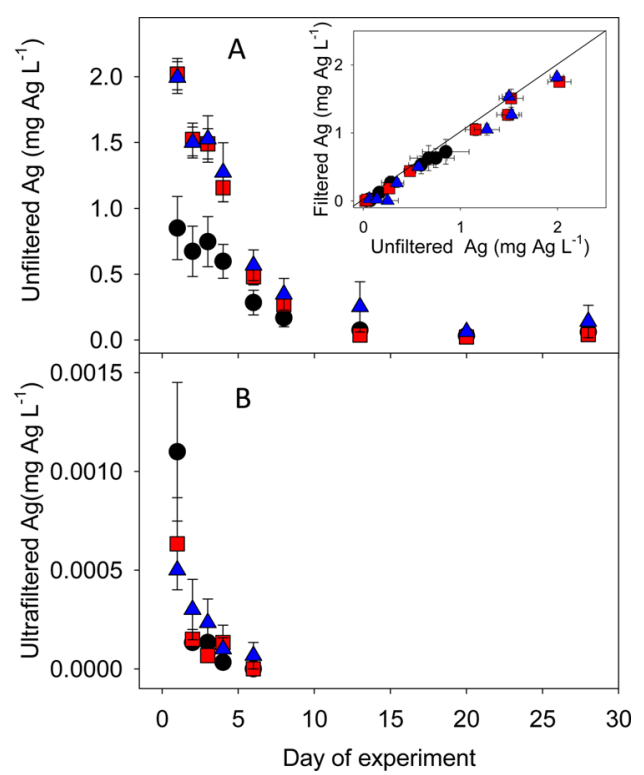

Figure 1. Silver concentrations declined over time in the water column in (A) total silver (inset is total silver vs $0.7 \mu \mathrm{m}$ filtered silver); (B) 3 $\mathrm{kDa}$ ultrafiltered silver. Samples for $3 \mathrm{kDa}$ ultrafiltered water were not presented past day 6 , as values were below our detection limit. The $\mathrm{AgNO}_{3}$ data are represented by black circles, GA-AgNPs by red squares, and PVP-AgNPs by blue triangles. Values are mean \pm SEM for $n=3$.

GA-AgNPs, PVP-AgNPs, and $\mathrm{AgNO}_{3}$, respectively (Figure 1A, SI Table S1; mean \pm standard error of the mean). Total silver concentrations declined most rapidly in the $\mathrm{AgNO}_{3}$ treatment, where $\mathrm{Ag}$ concentrations were significantly lower in the first 4 days following dosing $(p<0.05$, days $1-4)$. Despite their size and coating differences, there were no significant differences in water column silver concentration between the two AgNP treatments on any individual date. By day 6, silver concentrations in all $\mathrm{Ag}$ treatments had converged to $0.44 \pm$ $0.06 \mathrm{mg} \mathrm{Ag} \mathrm{L} \mathrm{L}^{-1}$. Total silver concentrations were nearly identical to samples filtered through $0.7 \mu \mathrm{m}$ filters for all three silver forms across all days, with a regression between filtered and unfiltered silver yielding an $r^{2}=0.993$. Between days 8 and 28, Ag concentrations in all Ag treatments remained fairly stable and were similar across treatments (averaging $0.13 \pm$ $0.02 \mathrm{mg} \mathrm{Ag} \mathrm{L}{ }^{-1}$ ).

Silver concentrations in the $<3 \mathrm{kDa}$ ultrafiltrate were 3 orders of magnitude lower than total or filtered silver concentrations. These concentrations did not differ significantly between Ag treatments on any date. Concentrations declined to below our detection limit $\left(<0.0005 \mathrm{mg} \mathrm{Ag} \mathrm{L}^{-1}\right)$ by Day 6, at which point we stopped measuring the ultrafiltrate fraction.

Organismal and Ecosystem Responses. Within 2 days of adding silver, we observed widespread leaf loss and browning of the submersed and floating aquatic plants within all Ag dosed mesocosms. All three of the dominant macrophytes ( $P$. diversifolius, E. densa, and L. punctata) showed visual evidence of toxicity, with a loss of photosynthetic pigments from the foliage. These qualitative changes were most apparent in the GA-AgNP and $\mathrm{AgNO}_{3}$ treatments, with a smaller fraction of foliage showing evidence of toxicity in the PVP-AgNP treatment (Figure 2), and stood in marked contrast to the controls. We observed a similar trend for phytoplankton, with cell densities declining in the three Ag treatments over the first 4 days (Figure 3). 


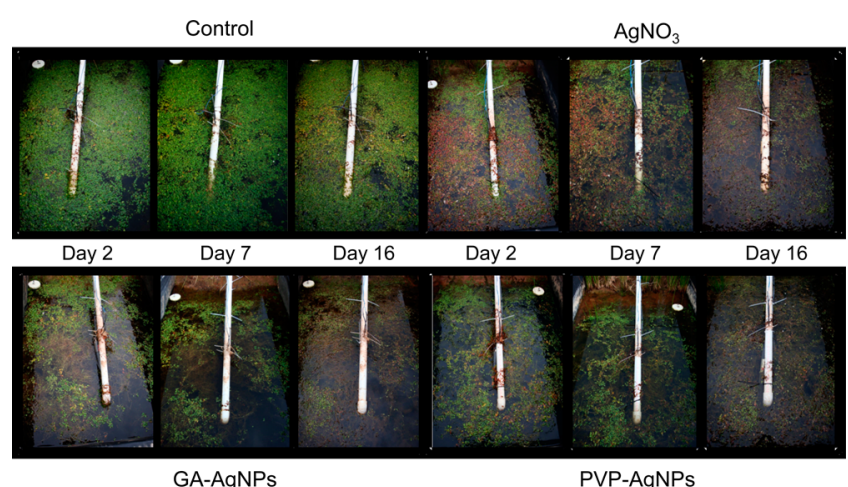

GA-AgNPs

PVP-AgNPs

Figure 2. Visual comparison of plant cover and health in response to silver additions. View is of the aquatic compartment of representative replicate mesocosms from Control, $\mathrm{AgNO}_{3}, \mathrm{GA}-\mathrm{AgNP}$, and PVPAgNP treatments from day 2, 7, and 16.

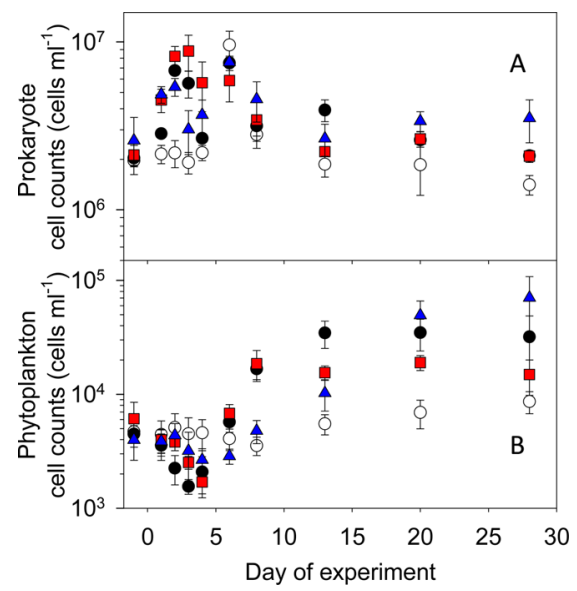

Figure 3. Planktonic prokaryotes (bacteria and archaea) and phytoplankton were differentially affected by silver treatments. Prokaryote (A) and phytoplankton (B) cell counts over time in the mesocosm water column. Controls are represented by white circles, $\mathrm{AgNO}_{3}$ by black circles, GA-AgNPs by red squares, and PVP-AgNPs by blue triangles. Values are mean \pm SEM for $n=3$ for silver treatments, and $n=4$ for Control.

This decline in macrophyte biomass was accompanied by a short-lived bloom of water column prokaryotes (bacteria and archaea), with water column cell densities increasing by three to 4-fold within a day of dosing in all silver treatments (Figure 3,
SI Table S2; $p<0.05$ as compared to controls on: day 1, GAAgNPs and PVP-AgNPs; day 2, all treatments; day 3, $\mathrm{AgNO}_{3}$, and GA-AgNPs). The largest increases in prokaryote abundance were observed in the GA-AgNP treatment, which maintained significantly higher prokaryote cell densities through day 4. A large increase in prokaryote cell numbers in all mesocosms on day 6 is attributed to an intense rain event (24 mm in $18 \mathrm{~min}$; SI Figure S1), which caused considerable erosion of soil particles and associated microbiota from the adjacent upland into the water column. No consistent treatment effects were observed subsequent to this event.

We observed new growth of macrophytes in all silver treatments by Day 16. While we lack quantitative measures of total plant biomass, we documented that $P$. diversifolius began producing new surface foliage as early as Day 9 in all $\mathrm{Ag}$ treatments, while $E$. densa was observed to have new shoots from old growth by Day 16 in all silver treatments. The phytoplankton also began increasing in abundance in all silver treatments (Figure 3B) giving significantly higher biomass for some portion of the time from days 8 to 28 compared to controls. The phytoplankton in the GA-AgNP treatment increased, but that increase was only marginally different from controls and converged with controls by day 13. In the $\mathrm{AgNO}_{3}$ treatment, phytoplankton increased to day 13, then leveled off and remained higher than controls through day 28. Phytoplankton abundance in the PVP-AgNP treatments showed a still different pattern, slowly increasing in abundance through day 28 , becoming significantly different from controls starting on day 20 .

In all three $\mathrm{Ag}$ treatments, tissue concentrations ranged from $93 \pm 7$ to $4180 \pm 250 \mathrm{mg} \mathrm{Ag} \mathrm{kg}^{-1}$ for macrophytes growing in the water column (E. densa, P. diversifolius, and L. punctata; Figure 4). Each species accumulated the highest concentrations of tissue $\mathrm{Ag}$ in the $\mathrm{AgNO}_{3}$ treatment, followed by GA-AgNPs, and then PVP-AgNPs, though the concentrations were not always significantly different between treatments (Figure 4). Treatment differences were most pronounced for E. densa, which consistently accumulated higher biomass $\mathrm{Ag}$ in all treatments over the first week (Figure 4). By day 28, tissue Ag concentrations had increased in P. diversifolius and L. punctata and declined in E. densa so that treatment and species differences were less apparent.

Dissolved Solutes and Gases. Within the first $24 \mathrm{~h}$ following dosing, dissolved organic carbon (DOC) increased 3fold in the $\mathrm{AgNO}_{3}$ and GA-AgNP treatments, rising by $20 \mathrm{mg}$

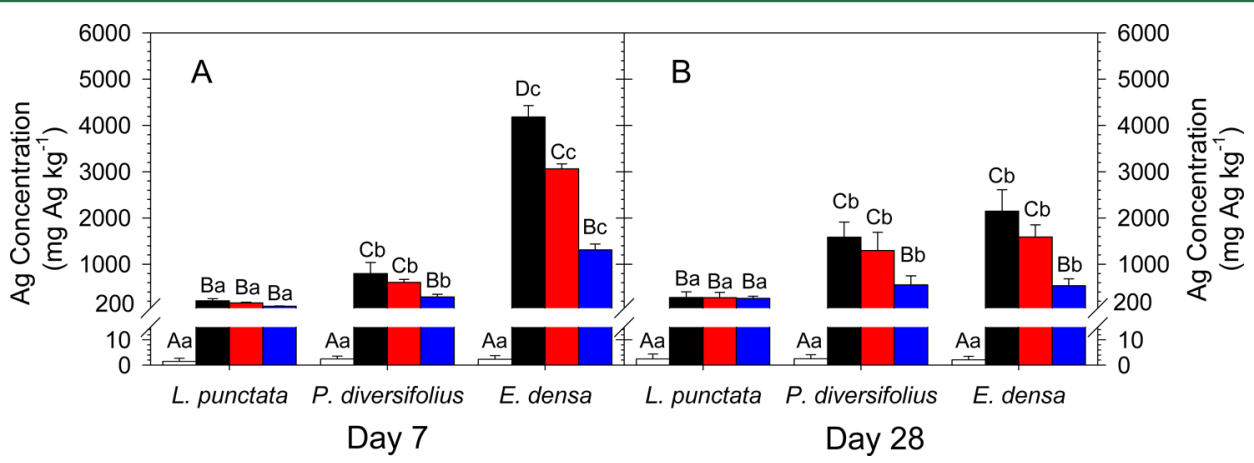

Figure 4. Silver concentrations in plants vary by species, treatment, and date. Data are presented for three aquatic plant species on day 7 (A) and day 28 (B). From left to right, white bars denote controls, black bars denote $\mathrm{AgNO}_{3}$, red bars denote GA-AgNPs, and blue bars denote PVP-AgNPs. The bars with the same capital letter (A, B, and C) are not significantly different $(\alpha=0.05)$ among treatments, and means with the same lowercase letter $(\mathrm{a}, \mathrm{b}$, and $\mathrm{c})$ are not significantly different $(\alpha=0.05)$ among species. Values are mean \pm SEM for $n=3$ for silver treatments, and $n=4$ for control. 
$\mathrm{C} / \mathrm{L}$ over the background concentration of $12.5 \pm 0.4 \mathrm{mg} \mathrm{C} / \mathrm{L}$ in both treatments. Concentrations of DOC were also elevated in the PVP-AgNP treatment, increasing by $\sim 50 \%$ above pretreatment concentrations. DOC concentrations were unchanged in the control mesocosms over this initial time period. These elevated DOC concentrations began to decline in all silver treatments on day 2, finally returning to a level equivalent to control mescosms by day 13 (Figure 5, SI Table S3). From day 13 to day 28, DOC concentrations increased in all mesocosms due to evaporative losses of water, but there were no differences between treatments.

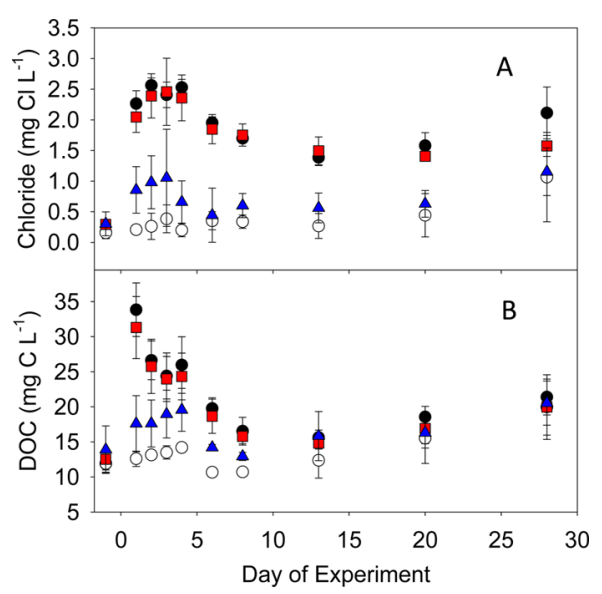

Figure 5. Following addition of silver, there was a rapid spike in chloride (A) and DOC (B). Controls are represented by white circles, $\mathrm{AgNO}_{3}$ by black circles, GA-AgNPs by red squares, and PVP-AgNPs by blue triangles. Values are mean $\pm \operatorname{SEM}$ for $n=3$ for silver treatments, and $n=4$ for Control.

Water column chloride $\left(\mathrm{Cl}^{-}\right)$also increased in all $\mathrm{Ag}$ treatments (Figure 5). The increase was similar for the $\mathrm{AgNO}_{3}$ and GA-AgNP treatments $\left(2.2 \pm 0.24 \mathrm{mg} \mathrm{Cl}^{-} \mathrm{L}^{-1}\right)$, and a less dramatic, but still significant increase in the PVP-AgNP treatment $\left(0.77 \pm 0.48 \mathrm{mg} \mathrm{Cl}^{-} \mathrm{L}^{-1}\right)$. Chloride concentrations varied very little $0.30 \pm 0.12$ in control mesocosms over the same period. Chloride concentrations subsequently declined in the Ag treatments from day 3 until day 13. At that point, $\mathrm{Cl}^{-}$ concentrations began to increase in all mesocosms through evaporative concentration. Treatment effects persisted to day 22 for GA-AgNPs, and through to day 28 for the $\mathrm{AgNO}_{3}$ treatment.

Water column dissolved oxygen concentration (DO) declined precipitously in both the $\mathrm{AgNO}_{3}$ and GA-AgNPs treatments, dropping to a minimum of $0.31 \pm 0.02 \mathrm{mg} \mathrm{O}_{2} \mathrm{~L}^{-1}$ in the $\mathrm{AgNO}_{3}$ on day 3 and $0.41 \pm 0.06 \mathrm{mg} \mathrm{O} \mathrm{L}^{-1}$ in the GAAgNPs on day 2 (Figure 6A, SI Table S4). In contrast, DO concentrations in control mesocosms never fell below $4.4 \mathrm{mg}$ $\mathrm{L}^{-1}$. Although DO declined slightly in the PVP-AgNP treatments, DO concentrations were never significantly different from controls. Dissolved oxygen concentrations remained significantly depressed through day 22 in GA-AgNPs and day 28 in $\mathrm{AgNO}_{3}$.

The decrease in $\mathrm{DO}$ was accompanied by dramatic increases in carbon dioxide $\left(\mathrm{CO}_{2}\right)$ concentrations in all three silver treatments. $\mathrm{CO}_{2}$ concentrations increased by $\sim 4000 \mathrm{ppmv}$ in the $\mathrm{AgNO}_{3}$ and GA-AgNPs treatments, and by $2300 \mathrm{ppmv}$ in the PVP-AgNP treatments by day 2, while concentrations in our controls remained $<2000$ ppmv of their pre-experiment

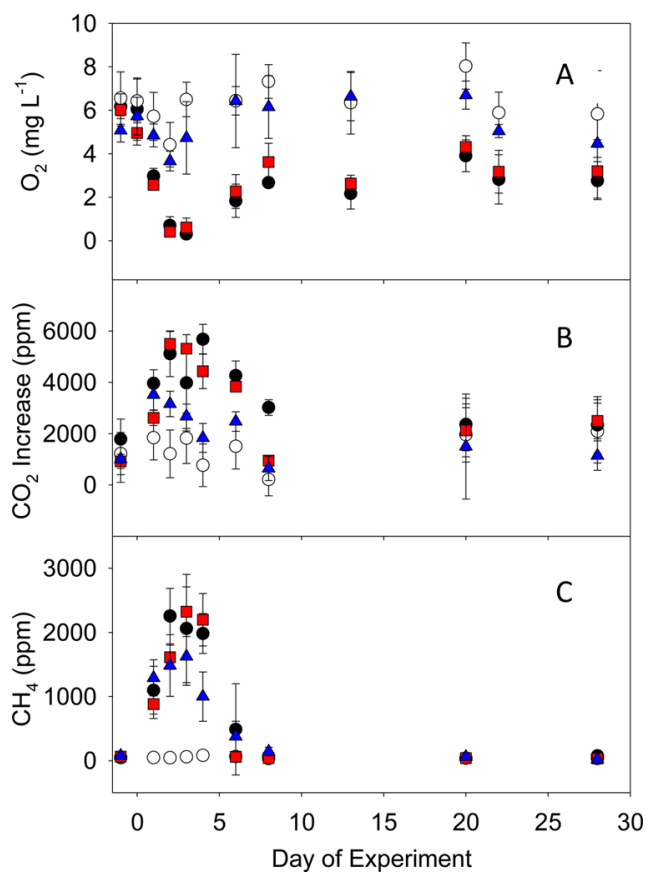

Figure 6. Following addition of silver, there was a drawdown in oxygen (A), and increase in $\mathrm{CO}_{2}(\mathrm{~B})$ and $\mathrm{CH}_{4}(\mathrm{C})$. Controls are represented by white circles, $\mathrm{AgNO}_{3}$ by black circles, GA-AgNPs by red squares, and PVP-AgNPs by blue triangles. Values are mean \pm SEM for $n=3$ for silver treatments, and $n=4$ for control.

concentrations (Figure 6, SI Table S4). The increase in dissolved $\mathrm{CO}_{2}$ was short-lived in the PVP-AgNP treatments, converging on controls by day 3 , but increases relative to controls were sustained in the GA-AgNP treatment through day 8 and in the $\mathrm{AgNO}_{3}$ treatment through day 20. There was also a small and short-lived but significant increase in $\mathrm{CO}_{2}$ associated with our GA-Control treatment on day 2. Among all measured parameters, this is the only one in which there was a divergence of a coating control from the control treatment, likely due to the respiration of gum arabic by microbes.

Produced by methanogenic archaea under anaerobic conditions, methane $\left(\mathrm{CH}_{4}\right)$ was present at low but measurable concentrations in all mesocosms prior to treatment (averaging $84 \pm 37 \mathrm{ppmv}$ ) but increased to extremely high concentrations of 2000 ppmv in all three silver treatments by the third day following dosing (Figure 6). In contrast to all other measured solutes and gases - which had similar trends between the three silver treatments but divergent magnitudes-both the magnitude and duration of increases in $\mathrm{CH}_{4}$ concentrations were similar for all three $\mathrm{Ag}$ treatments. All $\mathrm{Ag}$ treatments converged on the control concentration (averaging $52 \pm 16$ ppmv) by Day 6.

\section{DISCUSSION}

There were dramatic impacts at the organismal and ecosystem level in what is one of the most complete and realistic fully replicated environmental exposure experiments with nanomaterials to date. Both GA-AgNPs and their dissolved counterpart, $\mathrm{AgNO}_{3}$, caused several effects including: a rapid fold increase in DOC, $\mathrm{CO}_{2}$, and $\mathrm{Cl}^{-}$; and rapid depletion of $\mathrm{O}_{2}$ in the water column. The duration and direction of impacts were similar for the PVP-AgNP treatment; however, the magnitude of these changes were lower. However, in all three $\mathrm{Ag}$ treatments, there was a 40 -fold increase in $\mathrm{CH}_{4}$. 
Silver. On the basis of previous work, we expected that ionic $\mathrm{Ag}$ (added as $\mathrm{AgNO}_{3}$ ) would persist in the water column longer than AgNP-Ag, ${ }^{17}$ and that the GA-AgNPs would be more stable than the larger PVP-AgNPs, given their divergent distribution coefficients. ${ }^{33}$ Instead, water column Ag concentrations in the $\mathrm{AgNO}_{3}$ treatment decreased rapidly, falling by $67 \%$ of initial concentrations within $24 \mathrm{~h}$. In contrast, in the GA-AgNP and PVP-AgNP treatments, water column silver concentrations dropped by only $20 \%$ over $24 \mathrm{~h}$. In fact, $\mathrm{Ag}$ concentration over time of these two very different nanoparticles was nearly identical throughout the experiment.

We suggest that the discrepancy between the predicted and observed behavior of $\mathrm{AgNO}_{3}$ and AgNPs alike can be explained by the effects of all $\mathrm{Ag}$ treatments on submersed and floating macrophytes, which resulted in the release of large quantities of tissue derived $\mathrm{Cl}^{-}$and DOC to the water column. The extremely rapid decrease in $\mathrm{Ag}$ concentration in the first $24 \mathrm{~h}$ following $\mathrm{AgNO}_{3}$ addition could easily be attributed to the 13fold increase in water column $\mathrm{Cl}^{-}$concentrations in the $\mathrm{AgNO}_{3}$ treatments. While initial speciation modeling with background $\mathrm{Cl}^{-}$concentrations suggested that very little $\mathrm{AgCl}(\mathrm{s})$ would be formed, the same model suggests that at post-treatment $\mathrm{Cl}^{-}$ concentrations, nearly $82 \%$ of $\mathrm{Ag}$ would be expected to form $\mathrm{AgCl}(\mathrm{s})$ (SI Figure S2) either as colloids or as a precipitate. The release of the micronutrient $\mathrm{Cl}^{-}$from plant tissues was an unexpected treatment effect, but this explanation is realistic given that $\mathrm{Cl}^{-}$can be found at concentrations from 0.2 to $2 \%$ of dry plant mass. ${ }^{34}$ The increase in dissolved organic matter (DOM; quantified as DOC) in both AgNP treatments likely lead to their nearly identical concentrations during the first 30 days of this experiment $\left(r^{2}=0.997\right)$. The released DOM likely stabilized the relatively unstable PVP-AgNPs as primary particles. $^{21}$

For all three silver treatments, additional insight can be gained by calculating the rate constant for removal of silver for all three treatments, assuming first-order kinetics from day 1 through day 8 using the following equation:

$$
[\mathrm{Ag}]_{t}=[\mathrm{Ag}]_{0} * \mathrm{e}^{-k t}
$$

where $[\mathrm{Ag}]_{t}$ is the $\mathrm{Ag}$ concentration at time $t,[\mathrm{Ag}]_{0}$ is the calculated initial $\mathrm{Ag}$ concentration, and $k$ is the removal rate constant which is itself a composite of: aggregation; sedimentation; sorption/uptake by plants; and sorption/uptake by biofilms. Surprisingly, there were no significant differences in the rate constant between $\mathrm{AgNO}_{3}$, GA-AgNPs, and PVPAgNPs during this time period (1-way ANOVA, $p=0.629$ ), and $k$ averaged $0.21 \pm 0.066 \mathrm{day}^{-1}$ across all three silver treatments. This suggests that the processes driving $\mathrm{Ag}$ concentration may have been similar at later time points, despite having been dramatically different in the first $24 \mathrm{~h}$ between the $\mathrm{AgNO}_{3}$ and $\mathrm{AgNP}$ treatments. There are several hypotheses that could explain this: $\mathrm{Ag}^{+}$was likely rapidly transformed by $\mathrm{Cl}^{-}$released from macrophytes into small $\mathrm{AgCl}(\mathrm{s})$ colloids, ${ }^{35}$ which may have been stabilized by $\mathrm{DOM}^{36}$ and behaved similarly to the AgNPs; $\mathrm{Ag}^{+}$in the presence of $\mathrm{Cl}^{-}$and light ${ }^{37}$ or high concentrations of freshly derived plant $\mathrm{DOM}^{38}$ may have been reduced to $\operatorname{Ag}(0)$ nanoparticles in the watercolumn; or the factors driving $\mathrm{Ag}^{+}$ removal may have been mechanistically distinct from those driving AgNP removal, but may have been kinetically similar. However, with the data we have, it is not possible to readily distinguish between these hypotheses.
Plants accumulated high concentrations of silver after 7 days, with biomass silver concentrations ranging from a low of $93 \pm 7$ $\mathrm{mg} \mathrm{Ag} \mathrm{kg}$ in the floating L. punctata in the PVP-AgNP treatment, to a high of $4180 \pm 250 \mathrm{mg} \mathrm{Ag} \mathrm{kg}^{-1}$ for E. densa in the $\mathrm{AgNO}_{3}$ treatment. The highest silver concentration for AgNPs was for the GA-AgNPs treatments with E. densa at 3060 $\pm 250 \mathrm{mg} \mathrm{Ag} \mathrm{L}{ }^{-1}$. Concentrations of $\mathrm{Ag}$ in plants in PVPAgNP were generally half those found for the GA-AgNP, which may be due to higher bioavailability of the smaller GA-AgNPs. Regardless of whether it was due to uptake by plants, epiphytic biofilms, or sorption, ${ }^{39}$ plants were an important early sink of Ag.

Ecosystem Responses. On the basis of previous experiments, we had expected that the addition of $\mathrm{AgNPs}$ and $\mathrm{AgNO}_{3}$ would have divergent impacts with the effects of $\mathrm{AgNO}_{3}>\mathrm{GA}$ AgNPs > PVP-AgNPs. Furthermore, these effects were expected to be modest given our $2.5 \mathrm{mg} \mathrm{L}^{-1}$ concentration pulse exposure. ${ }^{7,16,17}$ As predicted, the effects of PVP-AgNPs were more modest than either GA-AgNPs or $\mathrm{AgNO}_{3}$. However, rather than the expected modest but divergent effects of the $\mathrm{AgNO}_{3}$ and GA-AgNP treatments, both led to a series of dramatic ecosystem level effects which were virtually identical for these two different forms of silver.

In both the $\mathrm{AgNO}_{3}$ and GA-AgNP treatments, there was a cascade of ecosystem level impacts, all with nearly identical magnitude. Initially, there was leaf senescence for the dominant macrophytes, together with declines in phytoplankton biomass. As autotrophs released an estimated $10 \%$ of their $\mathrm{C}$ into the water column as DOC in each of these two treatments, heterotrophic prokaryotes rapidly increased in abundance and consumed dissolved oxygen. Coupled with the loss of photosynthetic capacity, this drove the water column to hypoxia and significantly increased the water column concentrations of carbon dioxide. These ecological impacts were remarkably similar in both magnitude and timing between the GA-AgNP and $\mathrm{AgNO}_{3}$ treatments despite the fact that $\mathrm{AgNO}_{3}$ had a much more rapid initial decline in water column silver concentrations.

While PVP-AgNPs had modest or nonsignificant impacts on DOC, $\mathrm{CO}_{2}$, and $\mathrm{O}_{2}$, those impacts were always in the same direction as GA-AgNPs and $\mathrm{AgNO}_{3}$. Strangely, the most striking ecosystem level impact was nearly identical in all three silver treatments: dissolved methane increased 40-fold in all three silver treatments at 2-3 days after $\mathrm{Ag}$ addition. While conditions were primed for increased methane in the $\mathrm{AgNO}_{3}$ and GA-AgNP treatments (elevated DOC and $\mathrm{CO}_{2}$, depleted $\mathrm{O}_{2}$ ), in the PVP-AgNP treatment they were not, yet all three treatments had the same high elevated concentration of methane. These results suggest that the water column $\mathrm{CO}_{2}$, DOC, and DO concentrations were not the primary drivers of methane concentrations. We therefore speculate that the patterns in methane could have been the result of several different mechanisms: a direct effect of $\mathrm{Ag}$ on sensitive membrane bound methane monoxygenase enzymes used by the microbes that metabolize methane; ${ }^{18}$ an indirect effect of $\mathrm{Ag}$ on methanotrophs mediated by sediment dissolved oxygen and substrate concentrations; or the release of dissolved $\mathrm{CH}_{4}$ from plant biomass. ${ }^{40}$

Through our use of a mixed community of organisms in realistic environmental media and field conditions, our attempt to understand the impacts of nanoparticles on ecosystems led to surprising conclusions. Despite great dissimilarities in the form of silver added in each of the three silver treatments, 
overall they had similar effects, and all were removed rapidly from the water column, ending up in plants and sediment. The convergence we observed in terms of the impacts and fate of $\mathrm{Ag}$ was driven in large part by the cascade of biotic impacts and interactions that resulted from the Ag additions. Our most interesting findings, therefore, are the similarities between $\mathrm{AgNO}_{3}$ and AgNPs, and the surprising and dramatic impacts of the environment on $\mathrm{Ag}$ fate. While we expected the environment to impact the AgNPs, we did not anticipate the nature of that interaction to be a result of the original impacts of $\mathrm{Ag}$ on the environment.

\section{ASSOCIATED CONTENT}

\section{S Supporting Information}

Figures showing cumulative rainfall, and modeled silver speciation; additional details about mesocosm setup, sampling, sample handling, and sample analyses; tables detailing silver concentrations, phytoplankton and prokaryote densities, dissolved solutes, and watercolumn dissolved gases. This material is available free of charge via the Internet at http:// pubs.acs.org.

\section{AUTHOR INFORMATION}

\section{Corresponding Author}

*Phone: +1 (919) 660-7262; fax: +1 (919) 660-7293; e-mail: bpc8@duke.edu .

\section{Notes}

The authors declare no competing financial interest.

\section{ACKNOWLEDGMENTS}

The authors would like to especially thank Brooke Hassett and Medora Burke-Scoll for their help, patience, and the long hours they spent in the lab and the field. The authors would also like to thank a large number of individuals without whose help this project would not have been possible, including: Bonnie McGill, Sarah Anciaux, Eddie Liu, Charles Colbert, Hoelle Wiesner, Taylor Cater, Tyler Bray, Charles Delannoy, Shuwen $\mathrm{Ng}$, Corinne Williams, Adam Park Colman, Jeff Farner Budarz, Zach Hendren, Appala Raju Badireddy, Joel Meyer, Audrey Bone, Lee Bryant, Mariah Arnold, Richard Di Giulio, Helen Hsu-Kim, Amrika Deonarine, Wes Willis, Mengchi Ho, Andreas Gondikas, Katie Harold, Christina Arnaout, Mathieu Therezien, Shihong Lin, and Tammy Stern. The authors would also like to acknowledge NSF DBI 0959630 for funding the Environmental Cytometry Facility. This study was supported by the National Science Foundation (NSF) and the Environmental Protection Agency (EPA) under NSF Cooperative Agreement EF0830093, and the Center for the Environmental Implications of Nanotechnology (CEINT). Any opinions, findings, conclusions, or recommendations expressed in this paper are those of the authors and do not necessarily reflect the views of the NSF or the EPA. This work has not been subjected to EPA review and no official endorsement should be inferred.

\section{REFERENCES}

(1) Project on Emerging Nanotechnologies (2010) Nanotechnology Consumer Products Inventory. Available at: http://www. nanotechproject.org/inventories/consumer/.

(2) Blaser, S.; Scheringer, M.; Macleod, M.; Hungerbühler, K. Estimation of cumulative aquatic exposure and risk due to silver: Contribution of nano-functionalized plastics and textiles. Sci. Total Environ. 2008, 390, 396-409.
(3) Gottschalk, F.; Sonderer, T.; Scholz, R. W.; Nowack, B. Modeled environmental concentrations of engineered nanomaterials $\left(\mathrm{TiO}_{2}\right.$, $\mathrm{ZnO}, \mathrm{Ag}, \mathrm{CNT}$, fullerenes) for different regions. Environ. Sci. Technol. 2009, 43, 9216-9222.

(4) Nowack, B.; Ranville, J. F.; Diamond, S.; Gallego-Urrea, J. A.; Metcalfe, C.; Rose, J.; Horne, N.; Koelmans, A. A.; Klaine, S. J. Potential scenarios for nanomaterial release and subsequent alteration in the environment. Environ. Toxicol. Chem. 2012, 31, 50-59.

(5) Kaegi, R.; Voegelin, A.; Ort, C.; Sinnet, B.; Thalmann, B.; Krismer, J.; Hagendorfer, H.; Elumelu, M.; Mueller, E. Fate and transformation of silver nanoparticles in urban wastewater systems. Water Res. 2013, 47, 3866-3877.

(6) Kaegi, R.; Voegelin, A.; Sinnet, B.; Zuleeg, S.; Hagendorfer, H.; Burkhardt, M.; Siegrist, H. Behavior of metallic silver nanoparticles in a pilot wastewater treatment plant. Environ. Sci. Technol. 2011, 45, 3902-3908.

(7) Yin, L.; Cheng, Y.; Espinasse, B.; Colman, B. P.; Auffan, M.; Wiesner, M.; Rose, J.; Liu, J.; Bernhardt, E. S. More than the ions: The effects of silver nanoparticles on Lolium multiflorum. Environ. Sci. Technol. 2011, 45, 2360-2367.

(8) Navarro, E.; Piccapietra, F.; Wagner, B.; Marconi, F.; Kaegi, R.; Odzak, N.; Sigg, L.; Behra, R. Toxicity of silver nanoparticles to Chlamydomonas reinhardtii. Environ. Sci. Technol. 2008, 42, 89598964.

(9) Pradhan, A.; Seena, S.; Pascoal, C.; Cássio, F. Can metal nanoparticles be a threat to microbial decomposers of plant litter in streams? Microbial Ecol. 2011, 58-68.

(10) Choi, O. K.; Hu, Z. Q. Nitrification inhibition by silver nanoparticles. Water Sci. Technol. 2009, 59, 1699-1702.

(11) Throback, I. N.; Johansson, M.; Rosenquist, M.; Pell, M.; Hansson, M.; Hallin, S. Silver $\left(\mathrm{Ag}^{+}\right)$reduces denitrification and induces enrichment of novel nirK genotypes in soil. FEMS Microbiol. Lett. 2007, 270, 189-194.

(12) Bernhardt, E. S.; Colman, B. P.; Hochella, M. F., Jr.; Cardinale, B. J.; Nisbet, R. M.; Richardson, C. J.; Yin, L. An ecological perspective on nanomaterial impacts in the environment. J. Environ. Qual 2010, $39,1-12$.

(13) Keller, A. A.; McFerran, S.; Lazareva, A.; Suh, S. Global life cycle releases of engineered nanomaterials. J. Nanopart. Res. 2013, 15, 1-17.

(14) Andren, A. W.; Bober, T. W. Silver in the Environment: Transport, Fate, and Effects; SETAC: Pensacola, FL, 2002

(15) Colman, B. P.; Arnaout, C. L.; Anciaux, S.; Gunsch, C. K.; Hochella, M. F.; Kim, B.; Lowry, G. V.; McGill, B. M.; Reinsch, B. C.; Richardson, C. J.; Unrine, J. M.; Wright, J. P.; Yin, L.; Bernhardt, E. S. Low concentrations of silver nanoparticles in biosolids cause adverse ecosystem responses under realistic field scenario. PLoS One 2013, 8, e57189.

(16) Yin, L.; Colman, B. P.; McGill, B. M.; Wright, J. P.; Bernhardt, E. S. Effects of silver nanoparticle exposure on germination and early growth of eleven wetland plants. PLoS One 2012, 7, e47674.

(17) Colman, B. P.; Wang, S. Y.; Auffan, M.; Wiesner, M. R.; Bernhardt, E. S. Antimicrobial effects of commercial silver nanoparticles are attenuated in natural streamwater and sediment. Ecotoxicology 2012, 21, 1867-77.

(18) Arnaout, C. L.; Gunsch, C. K. Impacts of silver nanoparticle coating on the nitrification potential of Nitrosomonas europaea. Environ. Sci. Technol. 2012, 46, 5387-5395.

(19) Meyer, J. N.; Lord, C. A.; Yang, X. Y.; Turner, E. A.; Badireddy, A. R.; Marinakos, S. M.; Chilkoti, A.; Wiesner, M. R.; Auffan, M. Intracellular uptake and associated toxicity of silver nanoparticles in Caenorhabditis elegans. Aquatic Toxicol. 2010, 100, 140-150.

(20) Lowry, G. V.; Espinasse, B. P.; Badireddy, A. R.; Richardson, C. J.; Reinsch, B. C.; Bryant, L. D.; Bone, A. J.; Deonarine, A.; Chae, S.; Therezien, M. Long-term transformation and fate of manufactured Ag nanoparticles in a simulated large scale freshwater emergent wetland. Environ. Sci. Technol. 2012, 46, 7027-7036.

(21) Unrine, J. M.; Colman, B. P.; Bone, A. J.; Gondikas, A. P.; Matson, C. W. Biotic and abiotic interactions in aquatic microcosms 
determine fate and toxicity of $\mathrm{Ag}$ nanoparticles: Part 1-Aggregation and dissolution. Environ. Sci. Technol. 2012, 46 (13), 6915-6924.

(22) Cheng, Y.; Yin, L.; Lin, S.; Wiesner, M.; Bernhardt, E.; Liu, J. Toxicity reduction of polymer-stabilized silver nanoparticles by sunlight. J. Phys. Chem. C 2011, 115, 4425-4432.

(23) Kim, B.; Park, C. S.; Murayama, M.; Hochella, M. F., Jr. Discovery and characterization of silver sulfide nanoparticles in final sewage sludge products. Environ. Sci. Technol. 2010, 44, 7509-7514.

(24) Lombi, E.; Donner, E.; Taheri, S.; Tavakkoli, E.; Jämting, Å. K.; McClure, S.; Naidu, R.; Miller, B. W.; Scheckel, K. G.; Vasilev, K. Transformation of four silver/silver chloride nanoparticles during anaerobic treatment of wastewater and post-processing of sewage sludge. Environ. Pollut. 2013, 176, 193-197.

(25) Choi, O.; Cleuenger, T. E.; Deng, B. L.; Surampalli, R. Y.; Ross, L.; $\mathrm{Hu}, \mathrm{Z}$. Q. Role of sulfide and ligand strength in controlling nanosilver toxicity. Water Res. 2009, 43, 1879-1886.

(26) Reinsch, B. C.; Levard, C.; Li, Z.; Ma, R.; Wise, A.; Gregory, K. B.; Brown, G. E.; Lowry, G. V. Sulfidation of silver nanoparticles decreases Escherichia coli growth inhibition. Environ. Sci. Technol. 2012, 46, 6992-7000.

(27) Levard, C.; Hotze, E. M.; Lowry, G. V.; Brown, G. E. Environmental transformations of silver nanoparticles: Impact on stability and toxicity. Environ. Sci. Technol. 2012, 46, 6900-6914.

(28) Bard, C. C.; Murphy, J. J.; Stone, D. L.; Terhaar, C. J. Silver in photoprocessing effluents. J. (Water Pollut. Control Fed.) 1976, 389394.

(29) Hudson, F. Standard operating procedure: sample preparation and calculations for dissolved gas analysis in water samples using a GC headspace equilibration technique; U.S. Environmental Protection Agency: Washington, D.C., USA, 2004.

(30) Morse, J. L.; Ardón, M.; Bernhardt, E. S. Greenhouse gas fluxes in southeastern U.S. coastal plain wetlands under contrasting land uses. Ecol. Appl. 2012, 22, 264-280.

(31) Johnson, Z. I.; Shyam, R.; Ritchie, A. E.; Mioni, C.; Lance, V. P.; Murray, J. W.; Zinser, E. R. The effect of iron- and light-limitation on phytoplankton communities of deep chlorophyll maxima of the western Pacific Ocean. J. Mar. Res. 2010, 68, 283-308.

(32) Marie, D.; Partensky, F.; Jacquet, S.; Vaulot, D. Enumeration and cell cycle analysis of natural populations of marine picoplankton by flow cytometry using the nucleic acid stain SYBR green I. Appl. Environ. Microbiol. 1997, 63, 186-193.

(33) Hendren, C. O.; Badireddy, A. R.; Casman, E.; Wiesner, M. R. Modeling nanomaterial fate in wastewater treatment: Monte Carlo simulation of silver nanoparticles (nano-Ag). Sci. Total Environ. 2013, 449, 418-425.

(34) Broadley, M.; Brown, P.; Cakmak, I.; Rengel, Z.; Zhao, F. Chapter 7 - Function of Nutrients: Micronutrients. In Marschner's Mineral Nutrition of Higher Plants, (Third Edition); Marschner, P. , Ed.; Academic Press: San Diego; 2012, pp 191-248.

(35) Choi, O.; Deng, K. K.; Kim, N. J.; Ross, L.; Surampalli, R. Y.; $\mathrm{Hu}, \mathrm{Z}$. Q. The inhibitory effects of silver nanoparticles, silver ions, and silver chloride colloids on microbial growth. Water Res. 2008, 42, 3066-3074.

(36) Aiken, G. R.; Hsu-Kim, H.; Ryan, J. N. Influence of dissolved organic matter on the environmental fate of metals, nanoparticles, and colloids. Environ. Sci. Technol. 2011, 45, 3196-3201.

(37) Mokhtari, N.; Daneshpajouh, S.; Seyedbagheri, S.; Atashdehghan, R.; Abdi, K.; Sarkar, S.; Minaian, S.; Shahverdi, H. R.; Shahverdi, A. R. Biological synthesis of very small silver nanoparticles by culture supernatant of Klebsiella pneumonia: The effects of visible-light irradiation and the liquid mixing process. Mater. Res. Bull. 2009, 44, 1415-1421.

(38) Li, S.; Shen, Y.; Xie, A.; Yu, X.; Qiu, L.; Zhang, L.; Zhang, Q. Green synthesis of silver nanoparticles using Capsicum annuum $\mathrm{L}$. extract. Green Chem. 2007, 9, 852.

(39) Pietrobelli, J. M. T. de A.; Módenes, A. N.; Fagundes-Klen, M. R.; Espinoza-Quiñones, F. R. Cadmium, copper and zinc biosorption study by non-living Egeria densa biomass. Water Air Soil Pollut. 2009, $202,385-392$.
(40) Sorrell, B. K.; Downes, M. T. Water velocity and irradiance effects on internal transport and metabolism of methane in submerged Isoetes alpinus and Potamogeton crispus. Aquat. Botany 2004, 79, 189202. 